\title{
An Inflammatory Fibroid Polyp in the Hepatic Flexure of the Colon Treated with Argon Plasma Coagulation, Endoscopic Clipping and Polypectomy
}

\author{
Ariyo Ihimoyan Haritha Chelimilla Bhavna Balar \\ Division of Gastroenterology, Bronx-Lebanon Hospital, Bronx, N.Y., USA
}

Key Words

Inflammatory fibroid polyp · Polypectomy · Endoclipping · Argon plasma coagulation

\begin{abstract}
Inflammatory fibroid polyp (IFP) is a rare benign polypoid lesion of the gastrointestinal tract. Most IFPs occur in the stomach and colonic occurrence is very rare. Histologically IFP is characterized by a mixture of numerous small vessels, fibroblasts and edematous connective tissue associated with marked inflammatory infiltration by eosinophils. We present a rare case of a pedunculated IFP in the hepatic flexure of the colon treated successfully with a combination of argon plasma coagulation, endoclipping and polypectomy. A 74-year-old asymptomatic female underwent a screening colonoscopy in our hospital. A 12-mm pedunculated polyp was found at the hepatic flexure of the colon. After saline injection, we attempted to remove the polyp with a hot snare. However the polyp stalk was extremely difficult to resect despite several attempts with the hot snare. We placed an endoclip at the base of the stalk and then applied argon plasma coagulation at $1.0 \mathrm{l} / \mathrm{min}$ and $40 \mathrm{~W}$. After these measures we were able to resect the stalk and the polyp was retrieved. Histologically the polyp was located in the submucosa of the gastrointestinal tract. Proliferation of spindle cells and infiltration of inflammatory cells such as plasma cells and eosinophils were observed. The spindle cells were positive for CD34 and S100 but negative for c-kit and muscle markers. These findings are consistent with a histopathological diagnosis of IFP.
\end{abstract}




\section{Introduction}

Inflammatory fibroid polyp (IFP) is a rare benign polypoid lesion of the gastrointestinal tract. It can appear in many different locations in the gastrointestinal tract, the most common being the gastric antrum (70\%) followed by the small bowel (20\%); however it rarely occurs in the esophagus and colon [1]. Most colonic polyps tend to occur proximally and the macroscopic appearance is that of the pedunculated type in $68 \%$ of cases and of the sessile type in $32 \%$. It is characterized histologically by a mixture of numerous small vessels, fibroblasts and edematous connective tissue associated with marked inflammatory infiltration by eosinophils and plasma cells [2]. The fibroblasts appear as a spiral arrangement around the small vessels in a characteristic onion skin-like appearance. In the immunohistochemical stain, CD34 and S100 are often expressed in the stromal cells of IFP, but c-kit, CD68, p53 and Bcl-2 stains are not seen [3]. Negative staining for c-kit and Bcl-2 helps to differentiate IFPs from gastrointestinal stromal and solitary fibrous tumors. It is generally accepted that these cells are reactive with no malignant potential as neither recurrence nor metastasis has been observed [4]. IFPs originate primarily in the mucosa and submucosa but rarely spread to the muscular layer. They have no predilection for gender and occur in all age groups. Clinical symptomatology may depend on the macroscopic appearance of the lesion and its location in the gastrointestinal tract. Although there is no specific symptom associated with colonic IFP, abdominal pain and hematochezia are the most common symptoms. These benign pseudotumors continue to grow until they cause symptoms related to bleeding and obstruction. Surgical intervention is usually required for most symptomatic IFPs due to large size and submucosal involvement [5]. We herein report a very rare case of a colonic IFP managed with a combination of argon plasma coagulation, endoclipping and polypectomy.

\section{Case Report}

A 74-year-old woman was referred to our clinic service for colon cancer screening. She denied abdominal pain, irregular bowel habits or hematochezia. She had never had any endoscopic procedures in the past. She had no significant comorbidities and there was no family history of colon cancer or liver disease. She admitted to occasional alcohol intake but denied smoking or illicit drug use. Her home medications included aspirin and multivitamins. Physical examination revealed an overweight woman with a body mass index of 29 . Her abdomen was soft with no tenderness or palpable masses. No other abnormal findings were noted. Laboratory data revealed a hemoglobin level of $13.9 \mathrm{~g} / \mathrm{dl}$, a white blood cell count of $7,000 / \mu \mathrm{l}$ and serum creatinine of $0.5 \mathrm{mg} / \mathrm{dl}$. Serum alanine transferase and aspartate transaminase were 56 and $53 \mathrm{mg} / \mathrm{dl}$, respectively; serum albumin, alkaline phosphatase and bilirubin were normal. Hepatitis serology and autoimmune markers were negative. Basic metabolic test and coagulation profile were within normal limits. Abdominal ultrasound revealed mild hepatomegaly with fatty infiltration. We believed abnormal liver tests were secondary to fatty liver. A screening colonoscopy was subsequently performed. The colonoscopy revealed a 12-mm pedunculated polyp in the hepatic flexure of the colon (fig. 1). The polyp was suspected to be hyperplastic or adenomatous and we therefore proceeded to perform an endoscopic polypectomy. After saline injection, we attempted to use a hot snare to remove the polyp. However the polyp stalk was very difficult to resect despite several attempts with the hot snare. We then placed an endoclip at the base of the stalk and applied argon plasma coagulation at $1 \mathrm{l} / \mathrm{min}$ and $40 \mathrm{~W}$. After these measures the polyp stalk was successfully resected and the polyp was retrieved. Histological examination of the polyp revealed that it was of submucosal origin. Proliferation of spindle cells and infiltration of inflammatory cells such as eosinophils and plasma cells were observed (fig. 2). Immunohistochemically, the spindle cells were positive for CD34 in their cytoplasm and S100 protein 


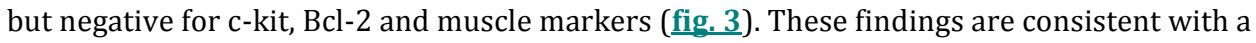
diagnosis of IFP.

\section{Discussion}

IFP was initially known as a proliferating lesion of unknown etiology with eosinophilic infiltration. It has been described in literature under a variety of names such as 'submucosal granuloma with eosinophilic infiltration', 'granuloblastoma' and 'eosinophilic granuloma'. Helwig and Ranier in 1953 first proposed the term 'inflammatory fibroid polyp' for this lesion [6]. It was originally believed to be a localized pattern of eosinophilic gastroenteritis, but in general IFP is a different disease entity. The etiology of IFPs is still unknown. The polyps are usually solitary, and although most commonly detected in adults they can be found in all age groups [6]. IFPs are most commonly located in the gastric antrum followed by the small bowel and rarely the esophagus and colon [7]. Endoscopically IFP is a smooth sessile or pedunculated polyp. Histologically IFP reveals cellular proliferation likely originating from the submucosa and is composed of fibrous and edematous stroma containing many variable-sized blood vessels, spindle cells and diffuse inflammatory cell infiltrate including eosinophils, plasma cells, lymphocytes, macrophages and mast cells [8,9]. The fibroblasts can gather in a nodular configuration with pseudogranulomatous or onion skin-like arrangements in which they form a concentric aggregation around small vessels and inflammatory infiltrates.

In our case immunohistochemistry using a panel of antibodies including CD34, CD68, c-kit, Bcl-2, S100 protein, p53 and smooth muscle actin was performed. The spindle cells were positive for CD34 but negative for c-kit, Bcl-2, CD68 and smooth muscle actin. Literature review shows that stromal cells of IFPs are often CD34immunoreactive but do not stain for c-kit [10]. Positive staining for CD34 differentiates IFP from inflammatory myofibroblastic tumors, while negative staining for c-kit and Bcl-2 differentiate IFP from gastrointestinal stromal and solitary fibrous tumors [9].

The pathogenesis of IFP remains unclear. Some authors have proposed that IFP is caused by an allergic reaction to inflammatory stimuli such as bacteria, chemicals, trauma etc., or is a reactive lesion of fibroblastic or myofibroblastic nature [11]. Others have proposed that IFP is neurogenic in nature [12]. IFP is generally regarded as a benign polyp with no malignant potential and a low recurrence rate. The main clinical features of colonic IFPs are abdominal pain (54\%), bloody stools (33\%), weight loss (21\%), diarrhea and anemia (17\%) [7]. Occasionally, large colonic IFPs may cause various complications such as intestinal obstruction and intussusception [5].

Colonic IFPs are predominantly treated with surgical resection and the use of endoscopic polypectomy is rare [13]. For pedunculated-type polyps, resection by endoscopic polypectomy is usually difficult because the stalk of the polyp is generally stiff. In our case, initial attempts to resect the polyp with a hot snare were unsuccessful. Endoclipping of the base of the polyp stalk, application of argon plasma coagulation and repeat hot snare polypectomy eventually resulted in the successful resection of the polyp. 
In conclusion, we report a rare case of colonic inflammatory polyp treated successfully with a combination of endoclipping, argon plasma coagulation and endoscopic polypectomy. Due to the benign nature of IFPs the number of cases treated endoscopically will likely increase in the future.

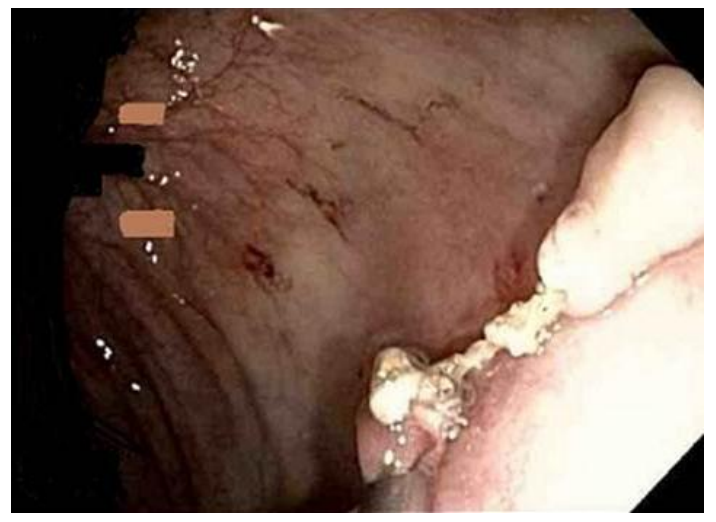

Fig. 1. A 12-mm pedunculated polyp in the hepatic flexure of the colon. The polyp stalk remained intact after multiple attempts to resect with a hot snare.

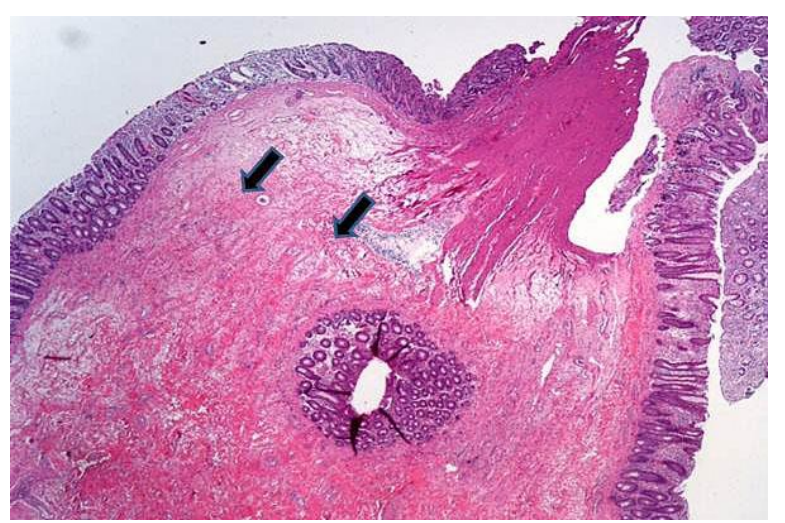

Fig. 2. Histopathology of the polyp showing proliferation of spindle cells and inflammatory cells (arrows). Magnification $\times 20$. 


\begin{tabular}{|c|c|c|c|}
\hline $\begin{array}{l}\text { Case Reports in } \\
\text { Gastroenterolocy }\end{array}$ & $\begin{array}{l}\text { Case Rep Gastroenterol 2012;6:63-68 } \\
\text { DOI: 10.1159/000336401 }\end{array}$ & $\begin{array}{l}\text { Published online: } \\
\text { January 28, } 2012\end{array}$ & $\begin{array}{l}\text { (c) } 2012 \text { S. Karger AG, Basel } \\
\text { ISSN } 1662-0631 \\
\text { www.karger.com/crg }\end{array}$ \\
\hline
\end{tabular}
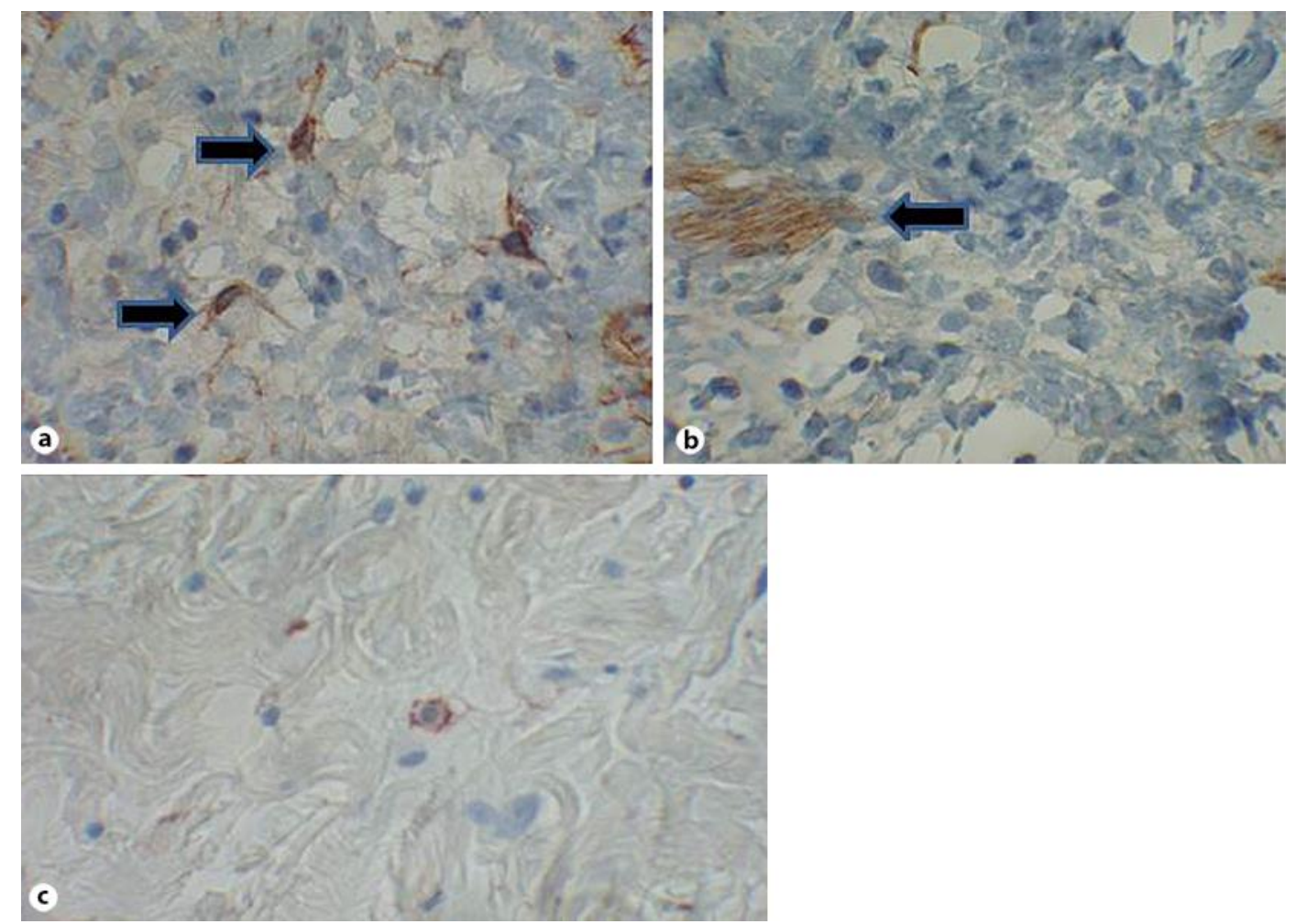

Fig. 3. Immunohistochemical stains of the polyp showing spindle cells positive for CD34 (arrows) (a), spindle cells positive for S100 (arrow) (b), and negativity for c-kit (c). Magnification $\times 40$.

\section{References}

1 Blackshaw AJ, Levison DA: Eosinophilic infiltrates of the gastrointestinal tract. J Clin Pathol 1986;39:1-7.

$\checkmark 2$ Kim YI, Kim WH: Inflammatory fibroid polyps of gastrointestinal tract. Evolution of histologic patterns. Am J Clin Pathol 1988;89:721-727.

3 Hasegawa T, Yang P, Kagawa N, Hirose T, Sano T: CD34 expression by inflammatory fibroid polyps of the stomach. Mod Pathol 1997;10:349-361.

-4 Stolte M, Finkenzeller G: Inflammatory fibroid polyp of the stomach. Endoscopy 1990;22:203-207.

-5 Gooszen AW, Tjon A, Tham RT, Veselic M, Bolk JH, Lamers CB: Inflammatory fibroid polyp stimulating malignant tumor of the colon in a patient with multiple hamartoma syndrome (Cowden's disease). AJR Am J Roentgenol 1995;165:1012-1013.

-6 Helwig EB, Ranier A: Inflammatory fibroid polyps of the stomach. Surg Gynecol Obstet 1953;96: 335-367.

7 De la Plaza R, Picardo AL, Cuberes R, Jara A, Martinez-Penalver I, Villanueva MC, Alias D, Osorio S, Pacheco E: Inflammatory fibroid polyps of the large intestine. Dig Dis Sci 1999;44:1810-1816.

-8 Eslami-Varzaneh F, Washington K, Robert ME, Kasgarian M, Goldblum JR, Jain D: Benign fibroblastic polyps of the colon: a histologic, immunohistochemical, and ultrastructural study. Am J Surg Pathol 2004;28:374-378.

9 Mahlouf HR, Sobin LH: Inflammatory myofibroblastic tumors (inflammatory pseudotumors) of the gastrointestinal tract: how closely are they related to inflammatory fibroid polyps? Hum Pathol 2002;33:307-315.

10 Kim MK, Higgins J: Expression of CD34, bcl-2 and kit in inflammatory fibroid polyps of the gastrointestinal tract. Appl Immunohistochem Mol Morphol 2000;8:147-153. 
11 Widgren S, Pizzolato GP: Inflammatory fibroid polyp of the gastrointestinal tract: possible origin in myofibroblasts? A study of twelve cases. Ann Pathol 1987;7:184-192.

12 Goldman Rl, Freidman NB: Neurogenic nature of so-called inflammatory fibroid polyps of the stomach. Cancer 1967;20:134-143.

13 Nakase H, Mimura J, Kawasaki T, et al: Endoscopic resection of small inflammatory fibroid polyp of the colon. Intern Med 2000;39:25-27. 